\title{
Studi Awal Pemanfaatan Kanal Jongaya dan Panampu Sebagai Transportasi Air di Kota Makassar
}

\author{
Ahmad Dahlan ${ }^{1}$, Slamet Trisutomo ${ }^{2}$ \\ ${ }^{1,2}$ Pengembangan Wilayah \& Kota, Fakultas Teknik Universitas Hasanuddin, Indonesia \\ E-mail:1alan.pwk@gmail.com, ${ }^{2}$ trisutomo@gmail.com
}

\begin{abstract}
Abstrak
Perkembangan jumlah kendaraan yang pesat di kota Makassar tidak diimbangi oleh pembangunan infrastruktur perkotaan khususnya pada sektor transportasi sehingga menimbulkan kemacetan, oleh karena itu dibutuhkan langkah-langkah strategis untuk menyelesaikan

Kata Kunci

Transportasi Kanal, Potensi, Masalah, dan Halte permasalahan tersebut salah satunya dengan mengembangkan transportasi alternatif dengan melihat potensi yang ada. Kota Makassar memiliki kanal Jongaya dan Panampu yang letaknya berada ditengah kota, membelah kota Makassar dari utara hingga selatan dan berfungsi sebagai drainase perkotaan. Penelitian ini bertujuan untuk mengungkap potensi dan masalah pada kanal jongaya dan panampu dalam perspektif pemanfaatannya sebagai transportasi air perkotaan, dan juga melihat hubungannya dengan moda transportasi lainnya dengan menentukan titik perhentian atau halte pada jalur kanal. Analisis yang digunakan dalam penelitian ini yaitu analisis kelayakan pelayaran kanal, analisis SWOT untuk kondisi lingkungan kanal, dan analisis penentuan lokasi halte. Dari hasil analisis tersebut dihasilkan beberapa kesimpulan yang akan menjadi rekomendasi atau arahan yang harus dilakukan sebelum melakukan kegiatan perencanaan transportasi pada kanal jongaya dan panampu kota Makassar.
\end{abstract}

\begin{abstract}
The rapid growth in the number of vehicles in the city of Makassar is not matched by the development of urban infrastructure especially in the transport sector, causing traffic jam. Therefore, it takes strategic steps to resolve these problems, one of them by developing alternative transportation by seeing the potential that exists. Makassar has Jongaya and Panampu canal that is located in the center of the city, divides the city from north to south and serves as urban drainage. This study aims to uncover the potential and problems of the Panampu and Jongaya canal in perspective of it's utilization as urban water transport, and also to see the relationship with the other transport modes by defining stop spots on the canal path. The analysis used in this research are, feasibility analysis of the canal for shipping, SWOT analysis for the environmental contition of the canal, and siting analysis for stops location. From this analysis, produced some conclusions that will become a recommendation or a referral that must be followed prior to the transportation planning activities in Panampu and Jongaya canal in Makassar.
\end{abstract}

\section{PENDAHULUAN}

Kota Makassar memiliki tiga kanal dengan panjang keseluruhan mencapai $15,11 \mathrm{~km}$, yang terdiri dari Kanal Jongayya $7,83 \mathrm{~km}$ yang bermuara pada laut sebelah barat kota Makassar, Kanal Panampu 4,92 km yang bermuara pada kawasan pelabuhan Potere sebelah utara kota, dan Kanal Sinrijala 2,36 km yang bermuara pada sungai Tallo sebalah timur kota Makassar.Kanal jongaya dan panampu dibatasi oleh kanal sinrijala. Sejak tahun 1990, Kanal ini berfungsi sebagai drainase perkotaan dan juga sebagai basis utama pengendalian banjir (Fisu, 2016). Seiring berjalannya waktu kondisi kanal makin mengalami penurunan fungsi dan juga penurunan kondisi fisik yang memprihatinkan, sangat terlihat jelas banyaknya sampah hampir diseluruh sisi kanal, kondisi airnya juga sudah tercemar dilihat dari warnanya berwarna hitam, bau yang ditimbulkan juga sangat busuk hal ini juga disebabkan oleh tidak adanya proses penyaringan air limbah dari pemukiman dan kawasan sekitar kanal lainnya, dan tingkat sedimentasi pada kanal yang tinggi sehingga terjadi pendangkalan pada kanal. Hal ini memberikan dampak negative terhadap warga yang bermukim di sekitar kanal dan mengganngu seluruh aktifitas yang terjadi pada wilayah tersebut.

Permasalahan ini harus segera diatasi karena akan menimbulkan dampak yang sangat besar bagi kehidupan perkotaan contohnya lingkungan yang akan tercemari oleh kendaraan yang jumlahnya semakin 
banyak, mempengaruhi kondisi perekonomian perkotaan karena terbuangnya waktu-waktu produktifitas di jalan. Hal ini membuat para perencana transportasi bekerja dengan keras agar masalah ini dapat teratasi secepatnya dengan melihat peluang-peluang yang ada.

Salah satu potensi yang bisa dimanfaatkan untuk memecahkan persoalan kemacetan yang terjadi di Kota Makassar yaitu memanfaatkan kanal sebagai media transportasi perkotaan baik itu sebagai perjalanan untuk kebutuhan sehari-hari (formal) maupun perjalanan kegiatan wisata (nonformal). Pembangunan atau pengembangan sarana transportasi juga dapat menimbulkan dampak positif terhadap suatu wilayah (Fisu, 2018) dan di sisi lain pertumbuhan aktivitas ekonomi akan mempengaruhi permintaan terhadap transportasi yang lebih banyak (Fisu. 2019). Kegiatan transportasi harus dilakukan secara menyeluruh dengan keterpaduan fisik antar moda berupa titik simpul pertemuan antar moda (Humang. 2016). Transportasi kanal menjadi salah satu solusi untuk mengurangi permasalahan kemacetan yang terjadi di kota Makassar, penelitian ini dilakukan untuk melihat potensi dan permasalahan yang terdapat pada kanal jongaya dan panampu dalam pemanfaatannya sebagai media transportasi perkotaan.

Sistem trasnsportasi secara menyeluruh (makro) dipecah menjadi beberapa sistem yang lebih kecil (mikro) yang saling terkait dan mempengaruhi yaitu sistem kegiatan (sistem mikro yang pertama) merupakan sistem tata guna lahan yang terdiri darisistem pola kegiatan sosial, ekonomi, kebudayaan, dan sebagainya.(sistem mikro yang kedua) yaitu sistem jaringan yang merupakan sarana (moda transportasi) dan prasarana (media) tempat moda transportasi bergerak, yaitu sistem jaringan jalan raya, kereta api, terminal bus, halte, bandara, dan pelabuhan. Adanya interaksi antara sistem kegiatan dan sistem jaringan akanmenghasilkan pergerakan manusia dan atau barang dalam bentuk pergerakan kendaraan dan atau orang (pejalan kaki). Pergerakan tersebut dikenal dengan sistem pergerakan (sistem mikro yang ketiga). Ketiga sistem mikro iniakan saling mempengaruhi. Untuk menjamin terwujudnya pergerakan yang aman, nyaman, cepat, murah, dan sesuai dengan lingkungannya, maka terdapat sistem mikro tambahan yang disebut dengan sistem kelembagaan yang terdiri dari pemerintah, swasta dan masyarakat.

Pada penelitian ini pemanfaatan kanal sebagai media transportasi air perkotaan tidak terlepas dari sistem transportasi di atas yaitu adanya kegiatan pada tata guna lahan di sekitar kanal, kapal sebagai angkutan orang atau barang, halte atau tempat perhentian penumpang sebagai sarana penunjang dalam sistem transportasi ini. Perangkutan diperlukan karena sumber kebutuhan manusia tidak terdapat disembarang tempat (Natsir, 2016). Penentuan lokasi halte pada jalur transportasi kanal jongaya dan panampu menjadi salah satu masalah yang diangkat dalam penelitian ini.

\section{METODOLOGI PENELITIAN}

\subsection{Teknik Pengumpulan Data}

Adapun teknik pengumpulan data pada penelitian ini adalah sebagai berikut:

1. Observasi lapangan

Pengumpulan data primer melalui observasi lapangan digunakan untuk melihat secara langsung masalah yang terdapat pada lokasi penelitian dan melihat potensi-potensi yang mendukung sebagai acuan pertimbangan penelitian ini.

2. Dokumentasi

Yaitu teknik pengumpulan data dengan cara pengambilan data yang diperoleh melalui dokumendokumen.

3. Metode pengumpulan data sekunder

Diperoleh dari instansi terkait, antara lain Bapedda, BPS, Dinas PU, serta penelusuran tinjauan pustaka dari buku dan internet.

\subsection{Metode Analisis}

Metode analisis yang digunakan dalam penelitian ini berdasarkan rumusan masalah yang telah dipaparkan adalah:

1. Analisis kelayakan pelayaran kanal

Analisis inidigunakan untuk memberikan gambaran tentang kelayakan pelayaran kanal berdasarkan data dan fakta-fakta yang ditemukan dilapangan. Dengan memaparkan dan mengidentifikasi potensi dan permasalahan yang dimiliki kanal Jongaya dan Panampu kota Makassar dalam perspektif pemanfaatannya sebagai transportasi air perkotaan. Indikator yang terdapat dalam proses analisis ini yaitu: 
a) Lebar alur kanal
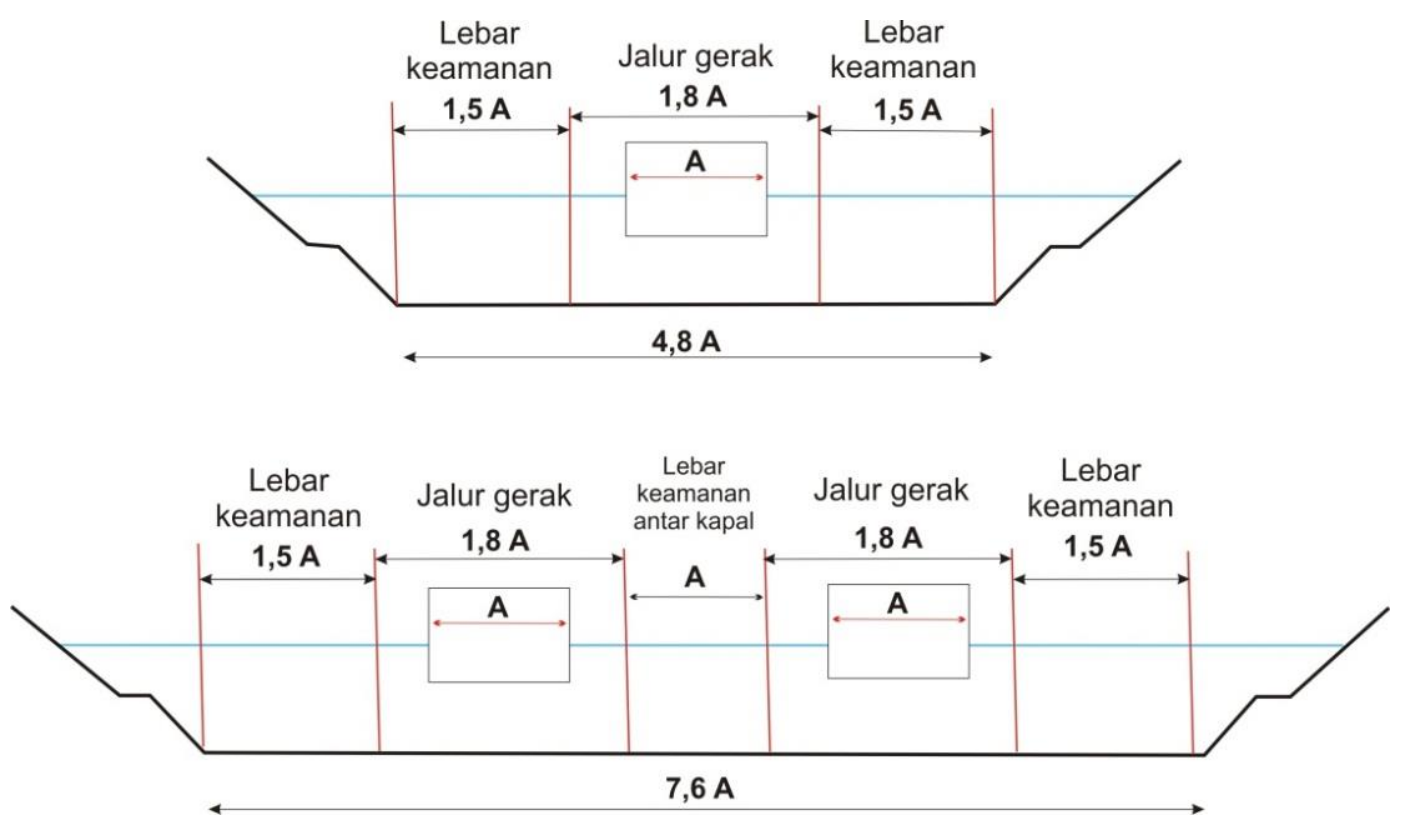

Gambar 1. Lebar Kelayakan Alur Pelayaran

(Sumber : http://id.wikibooks.org)

b) Kedalaman alur kanal

Kedalaman alur pelayaran secara umum dapat ditentukan dengan menggunakan rumus sebagai berikut :

$$
H=d+G+R
$$

Dimana:

$\mathrm{H}=$ Kedalaman alur, $\mathrm{m}$

$\mathrm{d}=$ draft kapal, $\mathrm{m}$

$\mathrm{G}=$ gerak vertikal kapal karena gelombang dan squat, $\mathrm{m}$

$\mathrm{R}$ = ruang kebebasan bersih untuk:

Kolam 7\%-15\% dari draft kapal

Alur 10\%-15\% dari draft kapal

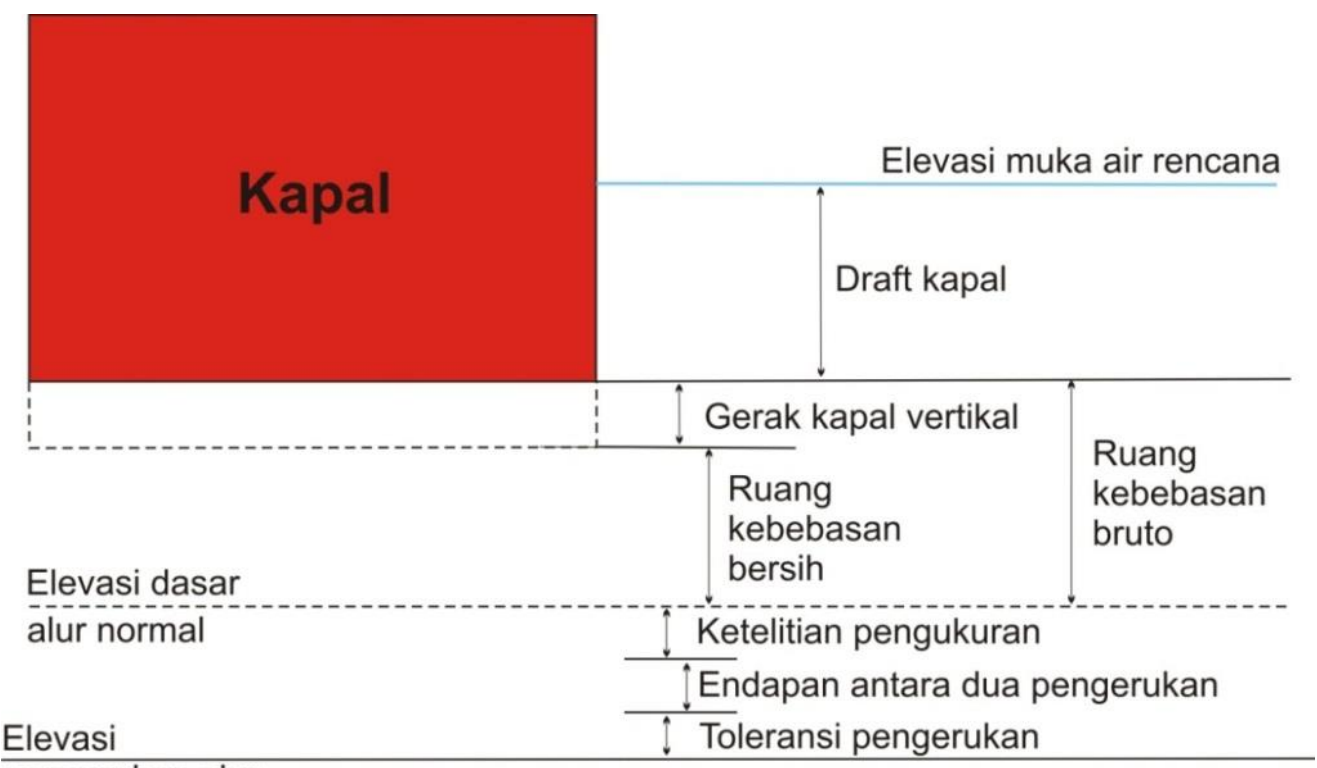

Gambar 2. Kedalaman Alur Pelayaran Ideal

(Sumber : http://id.wikibooks.org) 
c) Ruang bebas kapal di atas air

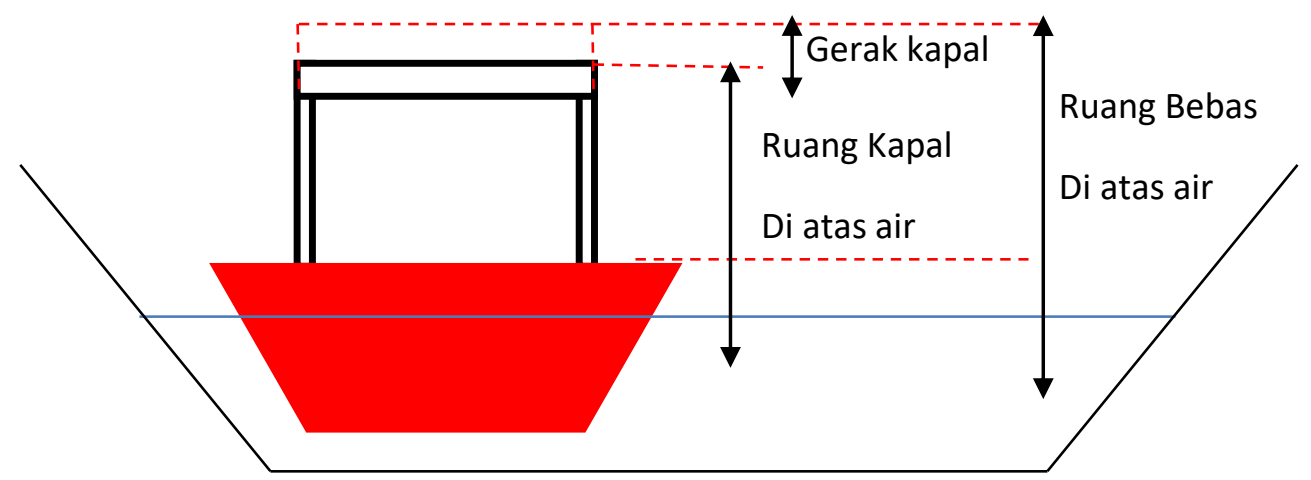

Gambar 3. Ruang Bebas Kapal Di Atas Air

(Sumber : http://id.wikibooks.org)

d) Kelayakan Lingkungan Kanal

Analisis ini untuk melihat bagaimana kondisi lingkungan kanal saat ini dan bagaimana kelayakan lingkungan kanal yang baik untuk dimanfaatkan sebagai media transportasi air perkotaan. Indikator yang menjadi penilaian pada analisis ini yaitu:

a. Sedimentasi atau endapan pada kanal

b. Kondisi air kanal

c. Bau yang ditimbulkan oleh kanal

Analisis ini akan dipaparkan dengan menggunakan metode penyajian foto dengan menunjukkan titik lokasinya pada peta. Analisis ini diorientasikan untuk mengetahui tingkat kelayakan kanal terhadap pengadaan transportasi air.

2. Analisis Penentuan Lokasi Halte

Analisis ini digunakan untuk mendapatkan hasil tentang teknik penempatan lokasi halte pada jalur kanal dengan indikator yaitu kodisi penggunaan lahan sekitar kanal sebagai titik - titik aktivitas atau kegiatan yang menjadi bangkitan dan tarikan pergerakan manusia, kondisi jaringan jalan darat, serta rute angkutan umum kota Makassar. Indikator tersebut yang akan digunakan untuk menentukan penempatan lokasi halte.

Analisis ini dipaparkan dengan menggunakan peta berdasarkan ketentuan dalam menentukan lokasi halte pada suatu lokasi. Dalam menentukan lokasi halte harus melihat beberapa indikator penting sebagai alasan untuk mentukan lokasi halte pada suatau jalur transportasi sesuai dengan tingkat aktifitas yang terdapat di dalamnya. 


\section{HASIL DAN PEMBAHASAN}

Analisis SWOT Untuk Kondisi Lingkungan Kanal

Analisis SWOT untuk kondisi lingkungan kanal merupakan salah satu metode yang digunakan untuk menentukan strategi yang tepat untuk mengatasi permasalahan lingkungan yang ada pada kanal jongaya dan panampu di Kota Makassar dengan mengungkap faktor internal kekuatan (strength) dan kelemahan (Weakness) serta faktoreksternal yang mempengaruhi kondisi lingkungan kanal yaitu peluang (opportunities) dan ancaman (thereath). Untuk lebih jelasnya dapat dilihat pada tabel matriks SWOT di bawah ini.

Tabel 1. Matriks Analisis SWOT Untuk Kondisi Lingkungan Kanal

\begin{tabular}{|c|c|c|}
\hline EKSTERNAL & $\begin{array}{l}\text { Kekuatan (Strenght) } \\
\text { S1. Bangunan yang terpisah dengan kanal oleh } \\
\text { jalan inspeksi } \\
\text { S2. Terdapat Alat Pengangkut sampah pada } \\
\text { muara kanal. }\end{array}$ & $\begin{array}{l}\text { Kelemahan (Weakness) } \\
\text { W1.Bangunan yang langsung berbatasan } \\
\text { dengan kanal dan membelakangi kanal. } \\
\text { W2.Kanal mengalami pendangkalan } \\
\text { W3.Air kanal yang kotor dan juga } \\
\text { menimbulkan bau busuk. } \\
\text { W4.tidak ada proses penyaringan dari outlet } \\
\text { drainase ke kanal. }\end{array}$ \\
\hline $\begin{array}{l}\text { Peluang (Opportunities) } \\
\text { O1.Dalam RTRW kota Makassar mengarahkan } \\
\text { melakukan penataan kanal dan penataan } \\
\text { lingkungan kanal pada kawasan permukiman } \\
\text { kumuh sepanjang bantaran kanal. } \\
\text { O2.Ada program pembersihan kanal oleh } \\
\text { pemerintah. } \\
\text { O3.Pengelolah kebersihan lingkungan kanal yaitu } \\
\text { masyarakat, pemerintah, dan swasta. }\end{array}$ & $\begin{array}{l}\text { Strenght - Opportunities (SO) } \\
\text { SO1. Melakukan Pengetatan penataan ruang pada } \\
\text { bantaran kanal. (S1 dan O1) } \\
\text { SO2. Pemerintah Khususnya dinas kebersihan } \\
\text { agar melakukan pemeriksaan secara intensif } \\
\text { terhadap alat pengangkut sampah pada } \\
\text { muara kanal. (S2 dan O1). }\end{array}$ & $\begin{array}{l}\text { Weakness - Opportunities (WO) } \\
\text { WO1.Pemerintah menganjurkan dalam } \\
\text { proses penataan bangunan bantaran } \\
\text { kanal agar tidak membelakangi kanal. } \\
\text { (O1 dan W1) } \\
\text { WO2.Pemerintah dan masyarakat } \\
\text { melakukan pengerukan dan } \\
\text { pembersihan kanal secara berkala. } \\
\text { (O1, O2, O3, dan W2, W3). } \\
\text { WO3.Pemerintah dan masyarakat } \\
\text { melakukan pembersihan dan } \\
\text { pengawasan terhadap sistem drainase }\end{array}$ \\
\hline
\end{tabular}




\begin{tabular}{|c|c|c|}
\hline & & $\begin{array}{l}\text { yang mengarah atau mengalir ke } \\
\text { kanal. (O1, O3, dan W1, W4) } \\
\text { WO4.Melakukan penghijauan dengan } \\
\text { menanam pohon dengan daya serap } \\
\text { carbon besar seperti pohon mahoni } \\
\text { dan pohon kihujan. (O1, O3, dan W3) } \\
\text { WO5.Mengadakan alat penyaringan dan alat } \\
\text { control pada tiap outlet drainase. (O3 } \\
\text { dan W4) }\end{array}$ \\
\hline $\begin{array}{l}\text { Ancaman (Thereath) } \\
\text { T1.Kegiatan Transportasi air dapat menyebabkan } \\
\text { lingkungan tercemar. } \\
\text { T2. Drainase pemukiman sekitar kanal } \\
\text { T3. Aktivitas pada sekitar wilayah kanal. }\end{array}$ & $\begin{array}{l}\text { Strenght - Thereath (ST) } \\
\text { ST1. Menggunakan moda transportasi yang ramah } \\
\text { lingkungan. } \\
\text { ST2. Kepada masyaraket dan pemerintah agar } \\
\text { menjadikan kanal sebagai elemen } \\
\text { lingkungan yang harus dijaga. } \\
\text { ST3. Perbaikan sistem drainase yang mengalir ke } \\
\text { kanal pada setiap bangunan sekitar kanal. } \\
\text { (S1 dan T2, T3). }\end{array}$ & $\begin{array}{l}\text { Weakness - Thereath }(\mathbf{W T}) \\
\text { WT1. Melakukan Proses perencanaan } \\
\text { secara terpadu : } \\
\text { 1. kebijakan pemerintah, } \\
\text { 2. kehidupan masyarakat, } \\
\text { 3. Aktifitas yang ada sekarang, } \\
\text { 4. Fungsi kanal yang baru, } \\
\text { 5. Infrastruktur, } \\
\text { 6. Limbah. } \\
\text { Yang kontekstual dengan ekosistem } \\
\text { kanal secara spasial. } \\
\text { WT2.Menumbuhkan Kesadaran bersama } \\
\text { kepada masyarakat sekitar kanal } \\
\text { untuk menjaga kelestarian kanal. }\end{array}$ \\
\hline
\end{tabular}

Sumber: Hasil Analisis Penulis 2011 
Salah satu langkah untuk menentukan strategi pengembangan yang akan dilakukan adalah dengan mengintreprestasikan faktor-faktor internal dan eksternal melalui interprestasi strenght (kekuatan), weakness (kelemahan), oppurtunity (peluang), dan threat (ancaman). Berikut ini merupakan analisis dengan metode SWOT pada kanal dalam perspektif transportasi air melalui proses telaah IFAS (Internal Strategic Faktors Analysis Summary) dan EFAS (Eksternal Strategic Faktors Analysis Summary) untuk kemudian diketahui posisi kedudukannya dalam kuadran SWOT.

Tabel 2. IFAS (Internal Strategic Faktors Analysis Summary)

\begin{tabular}{|c|c|c|c|c|}
\hline $\begin{array}{l}\text { Faktor } \\
\text { Internal }\end{array}$ & Keterangan & Bobot & Rating & $\begin{array}{r}\text { Bobot X } \\
\text { Rating }\end{array}$ \\
\hline \multirow{2}{*}{$\begin{array}{l}\text { Kekuatan } \\
\text { (Strenght) }\end{array}$} & $\begin{array}{l}\text { Bangunan yang terpisah dengan } \\
\text { kanal oleh jalan inspeksi }\end{array}$ & 0,75 & 4 & 3,0 \\
\hline & $\begin{array}{l}\text { Terdapat Alat Pengangkut } \\
\text { sampah pada muara kanal. }\end{array}$ & 0,25 & 2 & 0,5 \\
\hline \multicolumn{2}{|r|}{ Total } & 1,0 & & 3,5 \\
\hline \multirow{4}{*}{$\begin{array}{r}\text { Kelemahan } \\
\text { (Weakness) }\end{array}$} & $\begin{array}{l}\text { Bangunan yang langsung } \\
\text { berbatasan dengan kanal dan } \\
\text { membelakangi kanal. }\end{array}$ & 0,3 & 4 & 1,2 \\
\hline & Kanal mengalami pendangkalan & 0,2 & 3 & 0,6 \\
\hline & $\begin{array}{l}\text { Air kanal yang kotor dan juga } \\
\text { menimbulkan bau busuk. }\end{array}$ & 0,2 & 3 & 0,6 \\
\hline & $\begin{array}{l}\text { Tidak ada proses penyaringan } \\
\text { dari outlet drainase ke kanal. }\end{array}$ & 0,3 & 4 & 1,2 \\
\hline \multicolumn{2}{|r|}{ Total } & 1,0 & & 3,6 \\
\hline
\end{tabular}

Sumber: Hasil Analisis Penulis 2012 
Tabel 3. EFAS (Eksternal Strategic Faktors Analysis Summary)

\begin{tabular}{|c|c|c|c|c|}
\hline $\begin{array}{c}\text { Faktor } \\
\text { Eksternal }\end{array}$ & Keterangan & Bobot & Rating & $\begin{array}{c}\text { Bobot X } \\
\text { Rating }\end{array}$ \\
\hline \multirow{3}{*}{$\begin{array}{c}\text { Peluang } \\
\text { (Opportunities) }\end{array}$} & $\begin{array}{l}\text { Dalam RTRW kota Makassar } \\
\text { mengarahkan melakukan } \\
\text { penataan kanal dan penataan } \\
\text { lingkungan kanal pada } \\
\text { kawasan permukiman kumuh } \\
\text { sepanjang bantaran kanal. }\end{array}$ & 0,4 & 4 & 1,6 \\
\hline & $\begin{array}{l}\text { Ada program pembersihan } \\
\text { kanal oleh pemerintah. }\end{array}$ & 0,3 & 2 & 0,6 \\
\hline & $\begin{array}{l}\text { Pengelolah kebersihan } \\
\text { lingkungan kanal yaitu } \\
\text { masyarakat, pemerintah, dan } \\
\text { swasta. }\end{array}$ & 0,3 & 3 & 0,9 \\
\hline \multicolumn{2}{|r|}{ Total } & 1,0 & & 3,1 \\
\hline \multirow{3}{*}{$\begin{array}{l}\text { Ancaman } \\
\text { (Thereath) }\end{array}$} & $\begin{array}{lr}\text { Kegiatan } & \text { Transportasi air } \\
\text { dapat } & \text { menyebabkan } \\
\text { lingkungan } & \text { tercemar. }\end{array}$ & 0,4 & 4 & 1,6 \\
\hline & Outlet Drainase. & 0,3 & 3 & 0,9 \\
\hline & $\begin{array}{l}\text { Aktivitas pada sekitar } \\
\text { wilayah kanal. }\end{array}$ & 0,3 & 3 & 0,9 \\
\hline \multicolumn{2}{|r|}{ Total } & 1,0 & & 3,4 \\
\hline
\end{tabular}

(Sumber: Hasil Analisis Penulis 2012)

Berdasarkan penilaian tersebut di atas dengan menggunakan IFAS dan EFAS SWOT, maka diketahui posisi dalam kuadran SWOT, yaitu:

$$
\begin{aligned}
\mathrm{X} & =\text { Kekuatan }+ \text { Kelemahan } \\
& =3,5+(-3,6) \\
& =-0,1 \\
\mathrm{Y} & =\text { Peluang }+ \text { Ancaman } \\
& =3,1+(-3,4) \\
& =-0,3
\end{aligned}
$$




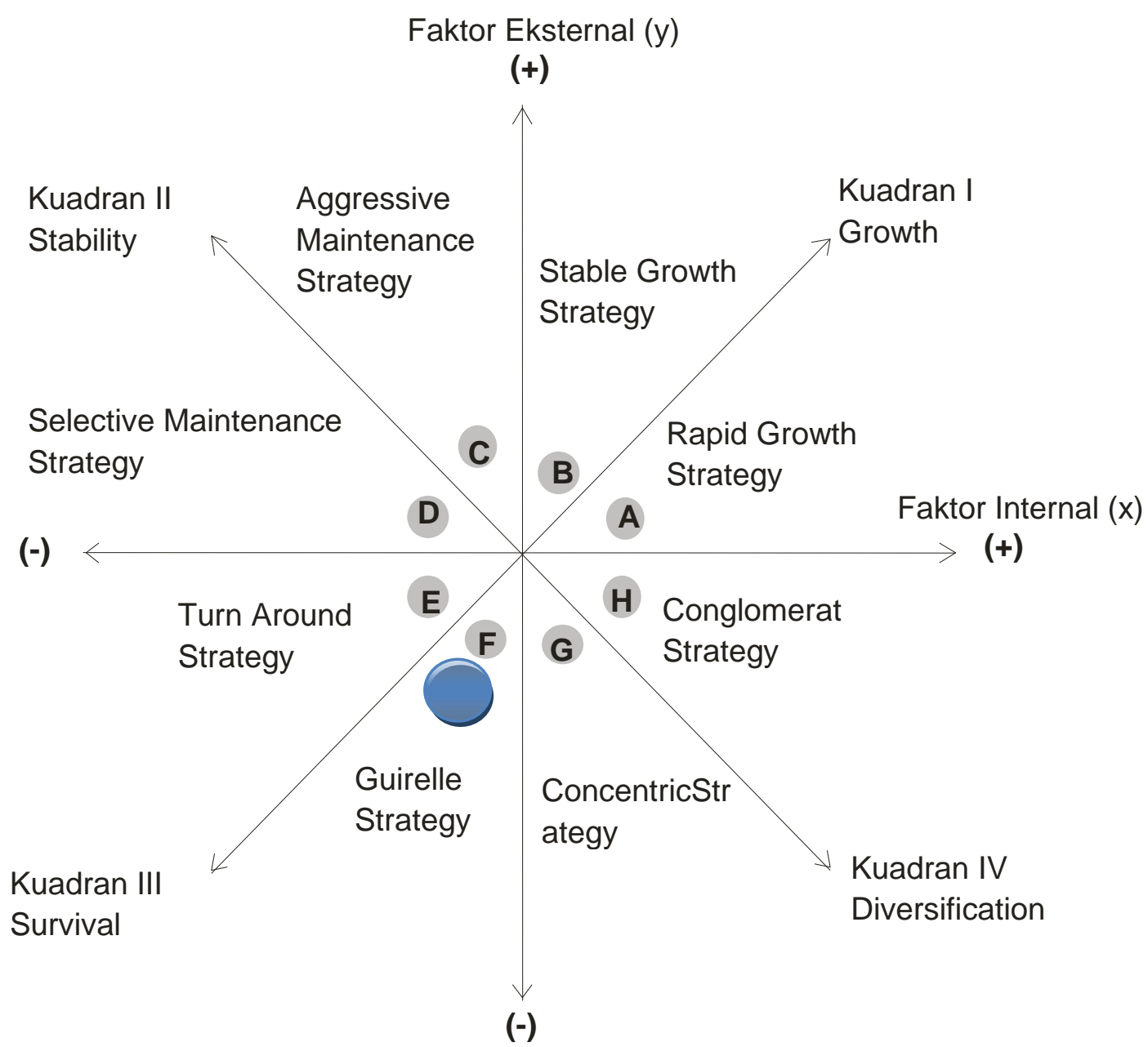

Gambar 4. Posisi Kondisi Lingkungan Kanal pada Kuadran SWOT (Sumber :Hasil Analisis Penulis 2012)

Berdasarkan kedudukannya dalam kuadran SWOT, maka titik EFAS dan IFAS untuk kondisi lingkungan kanal jatuh pada kuadran III ruang F dengan strategi dengan Guirelle Strategy, yaitu strategi gerilya, operasional dilakukan, diadakan pembangunan atau usaha pemecahan masalah dan ancaman.

Berdasarkan Analisis IFAS dan EFAS, pada kondisi lingkungan kanal terletak dikuadran III,maka prioritas strategi untuk kondisi lingkungan kanal jongaya dan panampu kota Makassar jatuh pada strategi WT (Weakness-Thereath) yaitu:

WT1. Melakukan Proses perencanaan secara terpadu untuk mengatasi masalah yang ada pada kanal jongaya dan panampu kota Makassar dalam pemanfaatannya sebagai media transportasi air yaitu: Kebijakan pemerintah, kehidupan masyarakat sekitar kanal, aktifitas masyarakat yang ada sekarang,

Fungsi kanal yang baru, ketersediaan infrastruktur, penanganan limbah.

Perencanaan Yang kontekstual dengan keberlangsungan kanal sesuai dengan fungsinya sebagai drainase perkotaan dan sebagai transportasi air nantinya.

WT2. Menumbuhkan Kesadaran bersama kepada masyarakat sekitar kanal untuk menjaga kelestarian kanal dengan mensosialisasikan pentingnya fungsi kanal sebagai pengendali banjir dan penyaluran air ke laut dan juga potensi yang dimiliki oleh kanal ketika menjadi transportasi air nantinya.

Penentuan Lokasi Halte

Kriteria Penentuan Lokasi Halte

Penentuan lokasi halte penumpang kendaraan umum dilakukan dengan memperhatikan rencana kebutuhan lokasi simpul jaringan aktifitas penumpang dan jalur kendaraan umum, serta perlu diperhatikan 
pula: Rencana umum tata ruang, kepadatan lalu lintas dan kapasitas jalan disekitar halte, keterpaduan antar moda transportasi, kondisi geografi loakasi halte dan kelestarian lingkungan

Selain itu sebaran lokasi halte harus memperhatikan bebagai aspek yang berkaitan dengan tuntutan umum (Suwardjoko P. Warpani, 2002) yaitu: pusat keramaiaan yang ada, misalnya pasar, pertokoan, objek wisata dan lain-lain, pusat kegiatan misalnya, kantor, sekolahan dan lain-lain, kemudahan perpindahan moda, misalnya persimpangan jalan

Persyaratan penentuan lokasi halte secara umum (Iskandar Abubakar dan kawan-kawan, 1995) adalah sebagai berikut: terletak pada jalur pejalan kaki/trotoar, dekat dengan pusat kegiatan yang membangkitkan pemakai angkutan umum, tidak tersembunyi, aman terhadap gangguan kriminal., harus ada pengatur pergerakan kendaraan, pemakai halte dan pejalan kaki, sehingga aman terhadap kecelakaan lalu lintas, tidak mengganggu kelancaran lalu lintas.

Selain persyaratan secara umum tersebut di atas, dapat dipergunakan pedoman praktis untuk penentuan lokasi halte: Jarak maksimal halte terhadap fasilitas penyebrangan pejalan kaki adalah 50 meter, tingkat pelayanan jalan, kecukupan lebar jalan, tinkat permintaan penumpang yang menentukan perlu tidaknya lindungan.

Jarak Antar Halte

Jarak antar halte (perhentian) merupakan jarak antara satu halte dengan halte berikutnya atau sebelumnya yang harus diperhatikan: Tidak terlalu jauh dan masih memungkinkan dijangkau seorang pejalan kaki dengan membawa barang bawaan, tidak terlalu dekat, dalam artian tidak menyulitkan pengoperasian kendaraan angkutan umum oleh pengemudi. kapasitas tempat henti (halte) dan adanya permintaan yang didasari kebutuhan.

Jarak antar halte (Departemen Perhubungan) dapat diatur seperti pada table di bawah ini:

Tabel 4. Jarak Antar Halte

\begin{tabular}{|c|l|l|l|}
\hline No. & \multicolumn{1}{|c|}{ Tata Guna Lahan } & \multicolumn{1}{|c|}{ Lokasi } & Jarak Halte $(\mathrm{m})$ \\
\hline 1. & $\begin{array}{l}\text { Pusat Kegiatan Sangat padat: Pasar, } \\
\text { Pertokoan }\end{array}$ & CBD, Kota & $200-300 *)$ \\
\hline 2. & Padat: Perkantoran, Sekolah, jasa. & Kota & $300-400$ \\
\hline 3. & Permukiman & Kota & $300-400$ \\
\hline 4. & $\begin{array}{l}\text { Campuran Padat: Perumahan, Sekolah, } \\
\text { jasa }\end{array}$ & Pinggiran & $300-500$ \\
\hline 5. & $\begin{array}{l}\text { Campuran Jarang: Perumahan, ladang, } \\
\text { sawah, tanah kosong }\end{array}$ & Pinggiran & $500-1000$ \\
\hline
\end{tabular}

Keterangan: *)= jarak $200 \mathrm{~m}$ dipakai bila sangat diperlukan saja, sedangkan jarak umumnya $300 \mathrm{~m}$.

(Sumber: Departemen Perhubungan)

Dalam penentuan lokasi halte ada banyak hal yang perlu diperhatikan menurut panduan yang sudah dibahas tadi. Untuk melihat lebih jelas penggunaan lahan dan aktifitas yang terdapat pada lokasi penelitian ini, maka wilayahnya dibagi menjadi 4 zona dalam menentukan lokasi-lokasi halte pada sepanjang jalur kanal Jongaya dan PanampuKota Makassar.

Penentuan Lokasi Halte

Dari pemaparan kriteria penentuan lokasi halte di atas dapat disimpulkan kriteria yang tepat untuk menentukan lokasi halte pada jalur kanal jongaya dan panampu berdasarkan gambaran kondisi yang telah dipaparkan dapat disimpulkan kriteria yang tepat untuk penentuan lokasi halte pada kanal jongaya dan panampu kota Makassar yaitu: Dekat dengan pusat-pusat aktifitas, keterpaduan antar moda transportasi lainnya, terletak pada jalan inspeksi kanal, lokasinya tidak tersembunyi dan aman dari tindakan kriminal. 


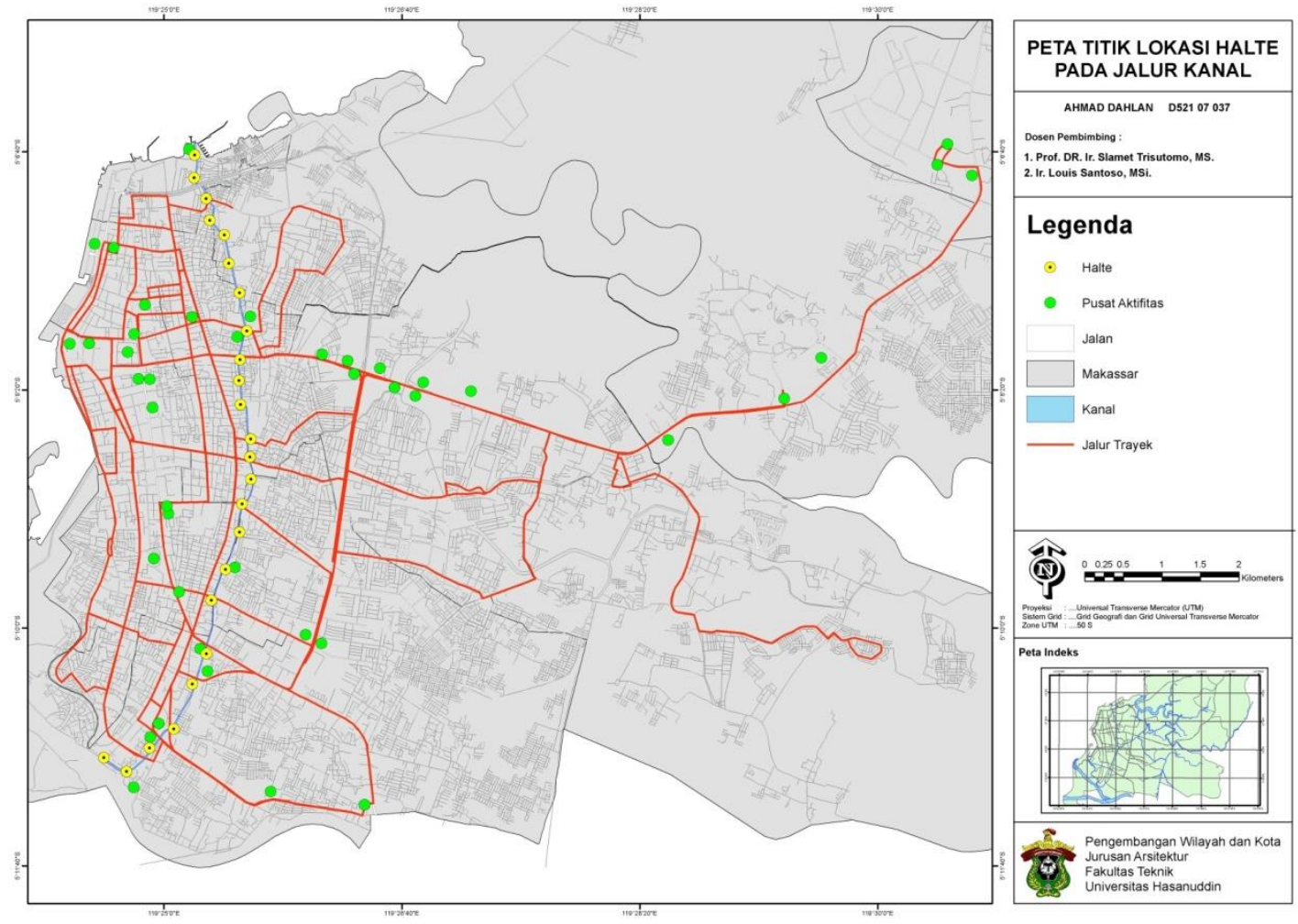

Gambar 5. Peta Titik Lokasi Halte Pada Jalur Kanal Jongaya dan Panampu (Sumber: Hasil Analisis 2012)

\section{KESIMPULAN DAN SARAN}

\subsection{Kesimpulan}

Berdasarkan hasil analisis yang dilakukan mengenai studi awal pemanfaatan kanal Jongaya dan Panampu sebagai transportasi air di kota Makassar didapatkan kesimpulan sebagai berikut:

1. Berdasarkan hasil analisis kelayakan pelayaran pada kanal Jongaya dan Panampu Kota Makassar yaitu:

a. Kelayakan lebar kanal yaitu hanya bisa dilalui oleh kapal jolloro dan kapal katinting, sedangkan kapal jukung dan kapal speed masih memungkinkan pada beberapa titik saja karena lebar kanal yang tidak sama dan berubah-ubah.

b. Kelayakan kedalaman kanal yaitu bisa dilalui oleh kapal jolloro, kapal jukung, kapal speed dan kapal katinting ketika kanal berada pada kondisi kedalaman kanal semuanya normal sesuai dengan data dari dinas pekerjaan umum kota Makassar yaitu 2 - 2,8 meter, namun kondisi eksisting kedalaman kanal yang ada sekitar $20 \%$ bagian kanal mengalami pendangkalan akibat sampah dan endapan lumpur.

c. Kelayakan Ruang bebas di bawah jembatan pada kanal hanya mampu dilalui oleh kapal katinting saja sedangkan kapal yang lain tidak memungkinkan untuk lewat, karena kecilnya ruang antara jembatan dengan permukaan air pada saat pasang.

d. Kelayakan lingkungan kanal yang dinilai adalah tingkat sedimentasi akibat sampah dan lumpur, air kanal dan bau yang ditimbulkan. Disimpulkan berdasarkan kondisi eksisting lingkungan kanal yaitu masih belum layak disebabkan oleh banyaknya endapan pada kanal akibat sampah dan lumpur sekitar $20 \%$ yang mengalami pendangkalan, warna air yang berwarna hitam akibat pembuangan limbah bangunan sekitar kanal yang mengalir melalui saluran drainase ke kanal tanpa ada proses penyaringan sebelum masuk kanal, bau busuk yang ditimbulkan akibat pembuangan sampah organik yang membusuk pada kanal terutama pada bagian pasar terong dan pasar pa'baengbaeng dan pada permukiman padat sekitar abu bakar lambogo dan kandea.

2. Analisis SWOT untuk untuk kondisi lingkungan kanal jatuh pada strategi WT (Weakness-Thereath) yaitu: 
a) Melakukan Proses perencanaan secara terpadu untuk mengatasi masalah yang ada pada kanal jongaya dan panampu kota Makassar dalam pemanfaatannya sebagai media transportasi air yaitu:

1. Kebijakan pemerintah,

2. Kehidupan dan aktifitasmasyarakat sekitar kanal

3. Fungsi kanal yang baru,

4. Infrastruktur,

5. Limbah.

Perencanaan Yang kontekstual dengan keberlangsungan kanal sesuai dengan fungsinya sebagai drainase perkotaan dan sebagai transportasi air nantinya.

b) Menumbuhkan Kesadaran bersama kepada masyarakat sekitar kanal untuk menjaga kelestarian kanal dengan mensosialisasikan pentingnya fungsi kanal sebagai pengendali banjir dan penyaluran air ke laut dan juga potensi yang dimiliki oleh kanal ketika menjadi transportasi air nantinya.

3. Analisis penentuan lokasi halte pada kanal jongaya dan panampu kota Makassar dilakukan dengan mengidentifikasi penggunaan lahan sekitar kanal sebagai bangkitan dan tarikan pergerakan, angkutan umum yang melintasi kanal untuk memudahkan proses perpindahan moda transportasi, keberadaan jalan inspeksi kanal. Hal tersebut menjadi kriteria dalam menentukan lokasi halte dengan jarak halte 300-500 meter maka diperoleh jumlah halte pada jalur kanal yaitu sebanyak 24 halte.

\subsection{Saran}

Setelah melakukan penelitian dan penulisan laporan, beberapa rekomendasi yang dapat dikemukakan adalah sebagai berikut:

1. Melakukan pelebaran kanal pada bagian kanal yang mengalami penyempitan menjadi 10 meter lebar minimumnya agar memungkinkan dilalui oleh kapal jukung, kapal jolloro, kapal spedd dan kapal katinting.

2. Untuk masalah kedalaman kanal yaitu dilakukan pengerukan pada bagian kanal yang mengalami pendangkalan secara bertahap dan berkala.

3. Ruang bebas di bawah jembatan pada kanal dilakukan pembesaran ruang yang tadinya $0,8 \mathrm{~m}$ menjadi 2,5 m agar dapat dilalui oleh kapal katinting, kapal jolloro, kapal speed, dan kapal jukung, dengan cara membuat struktur jembatan melengkung ke atas.

4. Untuk permasalahan lingkungan pada kanal perlu dilakukan beberapa hal yaitu:

a. Melakukan pengerukan kanal secara berkala.

b. Melakukan penataan bangunan pada bantaran kanal yang fasadenya membelakangi kanal menjadi menghadap kanal atau membuat 2 fasade bangunan.

c. Melakukan pembersihan dan pengawasan pada drainase yang mengalir ke kanal oleh pemerintah dan masyarakat.

d. Melakukan penghijauan dengan menanam pohon yang mampu menghisap gas karbon dengan jumlah yang besar seperti pohon mahoni atau pohon kihijau untuk mereduksi polusi udara yang terjadi.

e. Mangadakan alat penyaring pada outlet drainase dan melakukan kontrol secara berkala.

f. Menggunakan moda transportasi yang ramah lingkungan.

g. Melakukan perbaikan sistem drainase yang megalir ke kanal pada banguanan sekitar kanal.

5. Bagi Mahasiswa yaitu menjadi acuan untuk melakukan penelitian yang lebih mendalam lagi atau menjadi acuan untuk melakukan perencanaan transportasi pada kanal jongaya dan panampu kota Makassar.

\section{DAFTAR PUSTAKA}

Fisu AA. (2016). Potensi Demand Terhadap Pengembangan Kanal Jongaya dan Panampu Sebagai Moda Transportasi (Waterway) di Kota Makassar. Jurnal Manajemen Transportasi \& Logistik 3(3), 285 289.

Fisu AA. (2018). Analisis Kebutuhan Fasilitas Sisi Laut Pelabuhan terminal Khusus PLTGU Lombok. PENA

TEKNIK: Jurnal Ilmiah Ilmu-ilmu Teknik Vol 3 No 2, 197 - 206. 
Fisu AA. (2019). Tinjauan Kecelakaan lalu Lintas Antar Wilayah Pada Jalan Trans Provinsi Sulawesi Selatan. PENA TEKNIK: Jurnal Ilmiah Ilmu-ilmu Teknik Vol 4 No 1, 53 - 65.

Humang Windra Priatna \& Zulfadly. (2016). Analisis Keterpaduan Moda Transportasi Angkutan Penyeberangan dangan Jalan Raya di pelabuhan bajoe Kab. Bone. PENA TEKNIK: Jurnal Ilmiah Ilmu-ilmu Teknik Vol 1 No 1, 27 - 38.

Natsir, Rakhmawati (2016). Karakteristik kinerja Moda Angkutan Umum Kota Palopo (Studi Kasus Penumpang Bus Executive, Suspensi Udara, Scania - PO Bintang Prima. PENA TEKNIK: Jurnal Ilmiah Ilmu-ilmu Teknik Vol 1 No 2, 155 - 162.

Permata, Rizki,2008. Pergeseran Pergerakan Angkutan Sungai Di SungaiMartapura Kota Banjarmasin. Tugas Akhir Tidak Diterbitkan, Program Pascasarjana Magister Teknik Pembangunan Wilayah dan Kota, Universitas Diponegoro Semarang

Warpani, Suwardjoko. 1990. Merencanakan Sistem Perangkutan. Bandung: Penerbit ITB.

Susanto, 2005.Analisis Kebutuhan Dan Pemilihan Lokasi Halte Di Pintu Tol Padalarang. Tugas Akhir Tidak Diterbitkan, Program Pascasarjana Magister Teknik Sipil, Universitas Diponegoro Semarang

Arief, Rimba. 2009. Identifikasi Pergerakan Lalu Lintas Pasar Pabaeng-baeng. Tugas Akhir Tidak Diterbitkan, Program Studi Pengembangan Wilayah dan Kota, Fakultas Teknik Universitas Hasanuddin, Makassar

Sakti, Maulana. 2011. Pengaruh Hambatan Samping Sebagai Akibat Aktivitas Pasar Terhadap Tingkat Pelayanan Jalan Perintis Kemerdekaan Makassar (Studi Kasus : Mall M’Tos Dan Pasar Mandai). Tugas Akhir Tidak Diterbitkan, Program Studi Pengembangan Wilayah dan Kota, Fakultas Teknik Universitas Hasanuddin, Makassar 